\title{
SISTEM INFORMASI FRONT OFFICE UNTUK PENINGKATAN PELAYANAN PELANGGAN DALAM RESERVASI KAMAR HOTEL
}

\author{
Victor Marudut Mulia Siregar ${ }^{1)}$, Nancy Florida Siagian ${ }^{2 *)}$ \\ ${ }^{1}$ Teknik Komputer, Politeknik Bisnis indonesia \\ email: victor.siregar2@gmail.com \\ ${ }^{2}$ Keuangan dan Perbankan, Politeknik Bisnis Indonesia \\ *Korespondensi email: siagiannancyflorida@gmail.com
}

\begin{abstract}
The research aims to overcome the problem of managing customer data, room data, and transaction data manually at Hotel Fergael. The management of customer data, room data and transaction data that are processed manually, is overcome by building a Front Office Information System for hotel room reservations at Hotel Fergael. The results of the Front Office Information System research for hotel room reservations at the Fergael Hotel can be done quickly, effectively and efficiently at the receptionist's work time, making reports can also assist managers in seeing reservations that have or have occurred at the Fergael Hotel. The system is designed in the form of Visual Basic and uses a MySQL database. With this research, the receptionist can expedite the activities that run at the Fergael Hotel, especially room input, customer input, and room reservations that occur at the Fergael Hotel Pematangsiantar.
\end{abstract}

Keywords: Information System, Visual Basic, MySQL, Reservation, Hotel.

\section{PENDAHULUAN}

Pesatnya perkembangan teknologi dan ilmu pengetahuan memiliki dampak yang besar, khususnya pada bidang teknologi informasi yaitu mudah dan luasnya akses data maupun informasi yang ada di setiap instansi [1]-[8]. Hampir di setiap instansi perusahaan, organisasi, perkantoran, hotel, lembaga, maupun instansi pemerintahan membutuhkan pengolahan administrasi yang cepat, tepat, dan akurat, data serta informasi tersebut upaya peningkatan kinerja dari instansi tersebut [9]-[16], [17]-[21].

Industri Pariwisata merupakan sektor andalan dan menjadi salah satu pilihan yang baik untuk perkembangan ekonomi di Negara berkembang saat ini. Banyaknya fasilitas yang disediakan guna mendukung jalannya sektor pariwisata di Indonesia, juga dapat menjadi peluang besar bagi bangunan-bangunan yang digunakan sebagai tempat untuk menginap bagi pelancong ataupun turis, apabila dapat dikelola dengan baik dan sungguh-sungguh, seperti Hotel.

Hotel merupakan sejenis akomodasi yang menyediakan fasilitas dan pelayanan penginapan, makan dan minum, serta jasa jasa lainnya untuk umum yang dapat tinggal untuk sementara waktu, dan dikelola secara komersial. Dewasa ini hotel bukan hanya dapat digunakan bagi orang-orang yang sedang melakukan perjalanan atau menjalankan liburan saja, namun juga dapat dikunjungi oleh orang-orang yang sedang melakukan perjalanan bisnis.

Hotel Fergael merupakan hotel yang terletak di kawasan Jl. Medan Lintas Sumatera, yang merupakan hotel yang sedang berkembang dan saat ini berusaha untuk meningkatkan pelayanannya terhadap tamu hotel dan juga senantiasa berusaha meningkatkan standar kualitas hotel dari berbagai jenis pelayanan termasuk pelayanan pada front office hotel.

Pelayanan pada bagian front office hotel Fergael saat ini masih menggunakan sistem manual dalam melayani pemesanan kamar. Untuk peningkatan pelayanan terhadap pelanggan maka dirancang suatu sistem berbasis komputer agar bagian front office dapat dengan 
mudah merekam data transaksi pemesanan kamar dan juga mudah membuat laporan.

Penggunaan Sistem Informasi saat ini telah banyak diterapkan untuk mempermudah pekerjaan di berbagai bidang termasuk bidang perhotelan sehingga memberikan keunggulan dan keuntungan pada hotel dan pelayanan terhadap tamu menjadi lebih maksimal [22], [23]. Oleh sebab itu, dirancang sebuah sistem informasi yang berfungsi untuk mempermudah pekerjaan Front Office Hotel Fergael dalam mengelola pemesanan kamar hotel maupun pembuatan kwitansi maupun laporan-laporan lainnya. Dengan adanya Sistem Informasi Front Office untuk reservasi kamar hotel pada Hotel Fergael Pematangsiantar akan berdampak pada meningkatnya kinerja dan kualitas hotel tersebut.

\section{METODE PENELITIAN}

Tahapan yang dilakukan pada proses perancangan sistem aplikasi menggunakan alat bantu yang terdiri dari :

\section{Diagram Konteks}

Diagram konteks ini menunjukkan semua entitas luar yang menerima informasi dari atau memberikan informasi ke sistem. Pada gambar 1 terdapat diagram konteks sistem yang diusulkan.

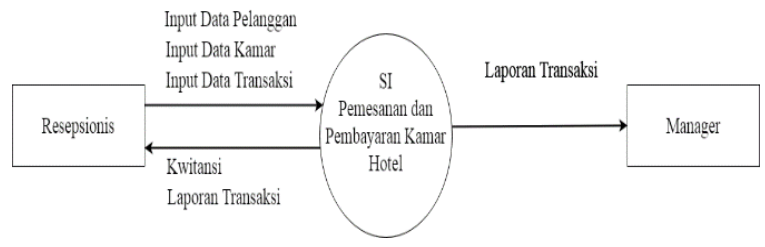

Gambar 1. Diagram Konteks yang diusulkan

Pada gambar 1 dijelaskan bahwa :

1. Pelanggan memberikan datanya agar dapat di input ke sistem oleh resepsionis ke dalam data pelanggan, lalu pelanggan dapat melakukan pemesanan kamar.

2. Data pelanggan dan data kamar dibutuhkan resepsionis guna menemukan pilihan kamar mana yang akan dipilih oleh pelanggan.
3. Resepsionis menginput data pelanggan dan data kamar ke dalam data transaksi yang berguna untuk mencetak (output) kwitansi bagi pelanggan.

4. Informasi tersebut akan dibebrikan kepada pelanggan guna mengetahui kamar apa yang t'lah dipesanan oleh pelanggan.

5. Resepsionis memberikan (output) laporan bagi manager agar manager mengetahui transaksi apa saja yang terjadi.

\section{Diagram ERD}

Diagram ERD merupakan relasi antar entitas yang digambarkan melalui diagram. Dengan adanya diagram ERD ini, struktur logis dari suatu basi data dapat gambarkan dengan jelas dan sederhana. Untuk lebih jelasnya dapat dilihat desain ERD seperti ditampilkan gambar 2.

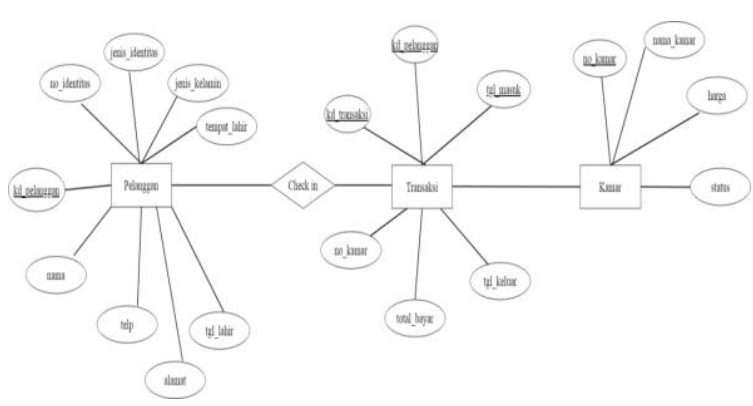

Gambar 2. Diagram relasi antar entitas (ERD)

\section{Perancangan Antarmuka (User Interface)}

Pada tahap ini dilakukan perancangan antarmuka yang merupakan bentuk rancangan tampilan sementara dari sistem front office yang akan dibangun. Melalui perancangan ini, penjelasan bagaimana tampilan yang digunakan akan kelihatan sehingga tampilan Sistem Informasi Front Office untuk reservasi kamar hotel ini dapat dirancang dengan baik. Hal ini dilakukan agar pembangunan sistem yang memenuhi prinsip perancangan antarmuka yang baik dapat dilakukan dengan mudah. Perancangan sistem informasi front office untuk pemesanan dan pembayaran kamar yang akan dibangun adalah sebagai berikut:

a. Desain Menu Utama (Resepsionis)

Desain Menu Utama digunakan agar Resepsionis dapat mengakses menu Transaksi dan 
Pelanggan.Desain menu utama dapat dilihat pada gambar 3.

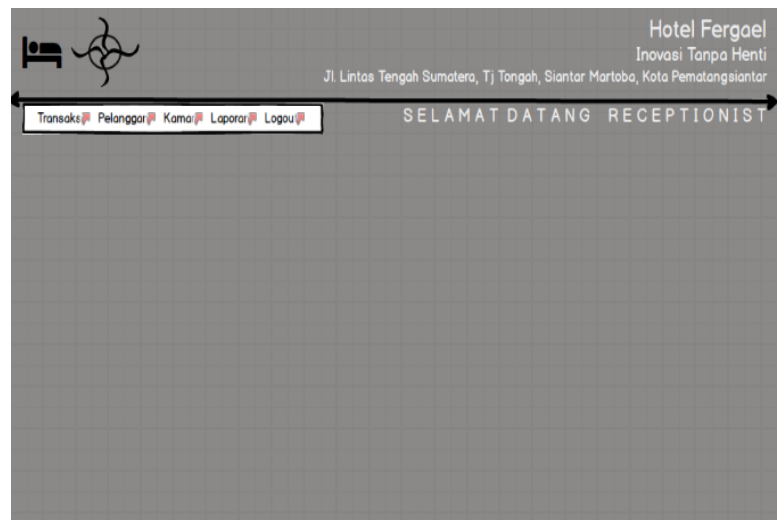

Gambar 3. Desain Form Menu Utama (Resepsionis)

b. Desain Menu Pelanggan (Resepsionis) Menu Pelangganadalah menu yang digunakan Resepsionis untuk menambahkandata diri pelanggan baru, mengedit sekaligus menghapus. Desain MenuPelanggan bagi Resepsionis dapat dilihat pada gambar 4 .

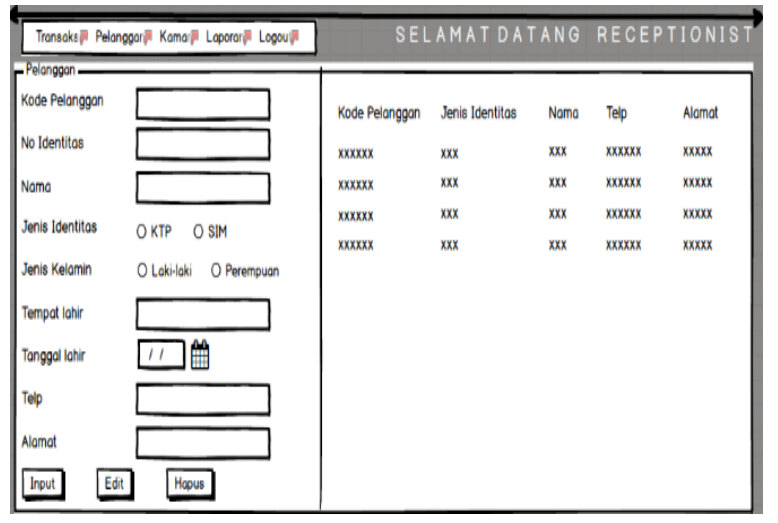

Gambar 4. Desain Form Menu Pelanggan (Resepsionis)

c. Desain Menu Transaksi (Resepsionis)

Menu Transaksi merupakan menu yang digunakan Resepsionis untuk mencatat data-data transaksi pelanggan sekaligus mencetaknya dalam bentuk kwitansi. Pada menu transaksi ini juga di desain agar bagian front office dapat menginput, mencetak, mengedit data pelanggan. Desain Menu Transaksi dapat dilihat pada gambar 5.

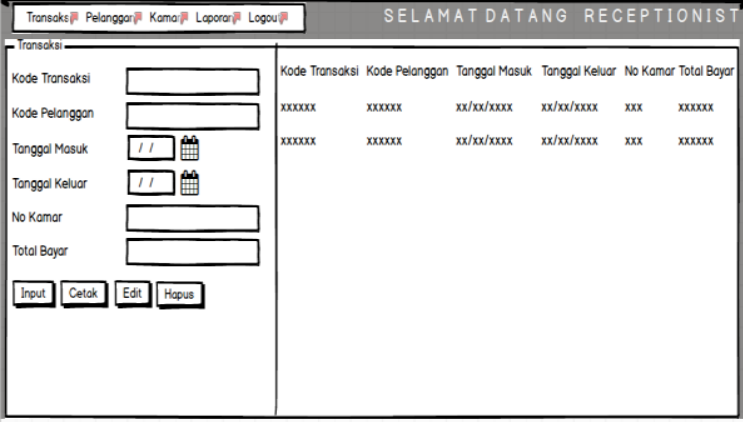

Gambar 5. Desain Form Menu Transaksi (Resepsionis)

d. Desain Menu Kamar (Resepsionis)

Menu Kamar merupakan menu yang digunakan Resepsionis sebagai bentuk informasi dari nomor, nama, harga dan status kamar agar resepsionis dapat lebih teliti guna menjelaskan kamar terhadap tamu. Desain Menu Kamar dapat dilihat pada gambar 6 .

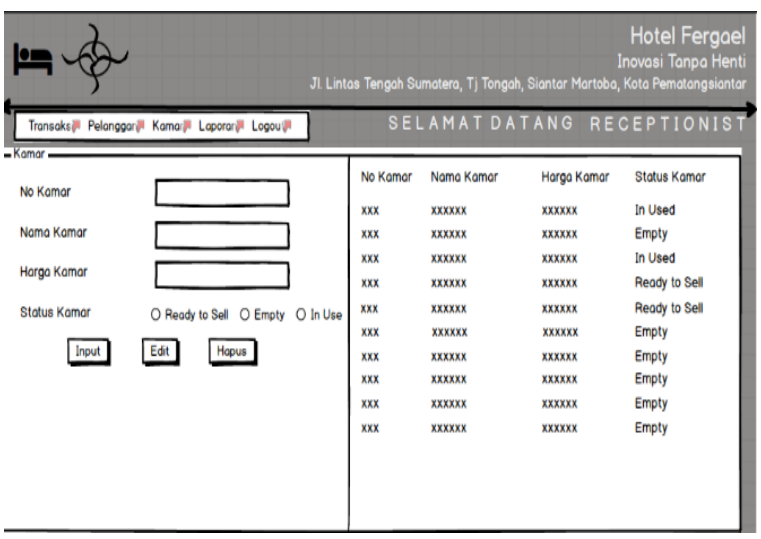

Gambar 6. Desain Form Menu Kamar (Resepsionis)

\section{HASIL DAN PEMBAHASAN}

Hasil dari Sistem informasi yang dibangun berisikan tampilan eksekusi program meliputi login, form (input system), dan report (output system) yang sudah berisikan data. Beberapa diantara tampilan tersebut terdiri dari:

\section{a. Halaman Menu Pelanggan}

Halaman ini merupakan halaman yang berisi data pelanggan dimana user dapat menambahkan data pelanggan baru, mengedit, dan menghapus data dengan mengklik tombol yang sudah disediakan. seperti pada gambar 7 . 


\begin{tabular}{|c|c|c|c|c|c|c|c|c|c|}
\hline 吗 File Mas & Transaksi & Laporan Tent & & & & & & & \\
\hline & & & & DATA PELAI & NGG & & & & \\
\hline Kode Pel & ggan & PLG-010 & & & & kd_pelanggan & no_identitas & jenis_identitas & jenis_kelamin \\
\hline Nomor Ic & ntitas & 12080204 & 04990007 & & & PLG-001 & $1207040323950 \ldots$ & KTP & Laki-Laki \\
\hline Jenis Ide & & & & & & PLG-003 & $\begin{array}{l}12097 / 0604940 \ldots \\
1206620404990 \ldots\end{array}$ & $\begin{array}{l}\text { KIP } \\
\text { KTP }\end{array}$ & \begin{tabular}{|l} 
Perempuan \\
Iakilaki
\end{tabular} \\
\hline & & . & Pि Peremnuar & & & PLG-004 & & SIM & Perempuan \\
\hline Jenis Kel & & Laḱ-Laki & rerempuan & & & PLG-005 & $1200310704940 \ldots$ & KTP & Laki-Laki \\
\hline Nama Pe & Iggan & Fahmi Re & & & & PLG-006 & & SIM & Perempuan \\
\hline Alamat & & Jl. Medan & & & & PLG-007 & $1209221703960 \ldots$ & KTP & Perempuan \\
\hline & & & & & & PLG-008 & 1203771106920... & KTP & Lakki-Laki \\
\hline Telepon & & 08229256 & 9233 & & & PLG-009 & 1200661307950... & KTP & Lakki-Laki \\
\hline Tempat L & & Pematang & siantar & & 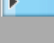 & FLOVIOU & $12000200404500 .$. & nir & 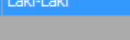 \\
\hline Tanggal I & & Sunday . & pril $\quad 04,1999$ & 唹 & & & & & \\
\hline$\checkmark$ Simpan & $X$ Hapus & (1) Batal & $\times$ Tutup & & 1 & III & + & & \\
\hline
\end{tabular}

Gambar 7. Halaman Menu Pelanggan

b. Halaman Menu Kamar

Halaman menu kamar ini digunakan untuk menginput, mengedit, mengubah, juga menghapus data kamar yang diinginkan. Tampilan halaman menu kamar dapat dilihat pada gambar 8 .

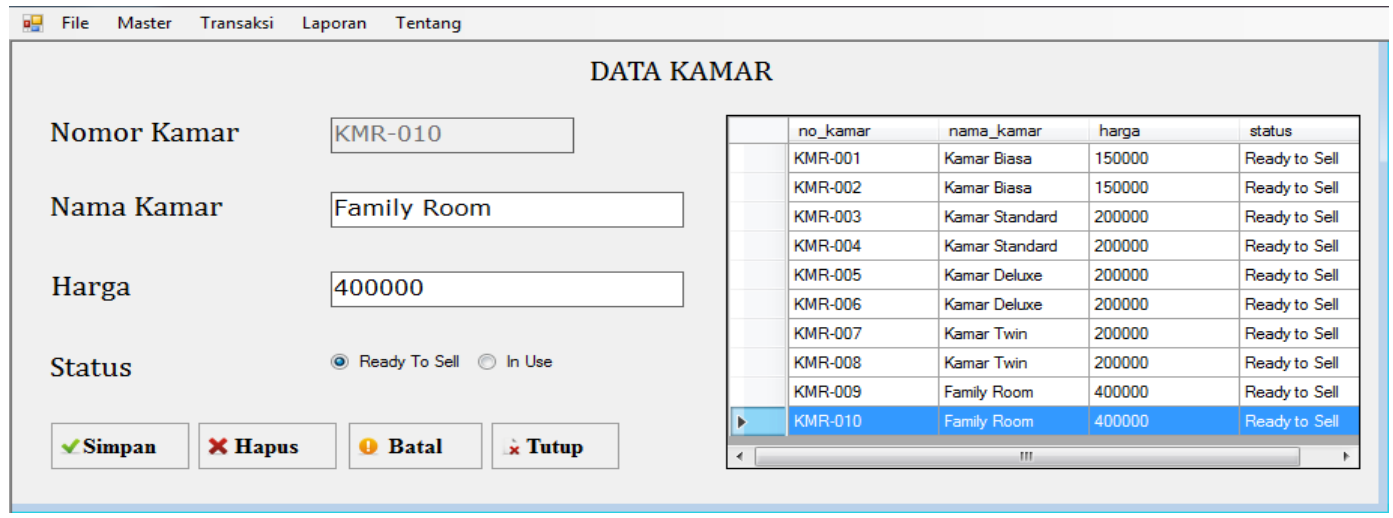

\section{Gambar 8. Halaman Data Kamar}

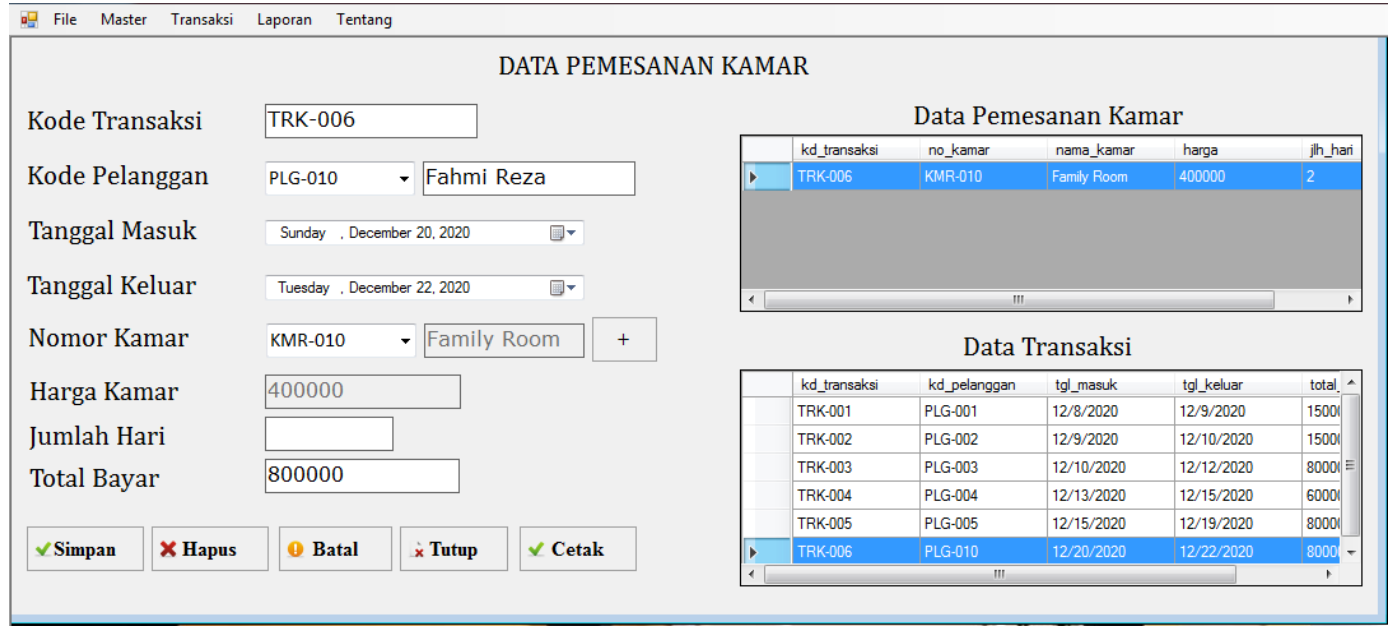

Gambar 9. Halaman Data Transaksi 
c. Halaman Data Transaksi

Halaman ini merupakan halaman yang berisi data transaksi yang sedang maupun telah terjadi yang mana user dapat menambah, mengedit, menghapus dan mencetak data transaksi dengan mengklik tombol yang sudah disediakan. Adapun halaman data transaksi dapat dilihat pada gambar 9 .

\section{KESIMPULAN}

Setelah merancang Sistem Informasi Front Office untuk reservasi kamar hotel pada Hotel Fergael Pematangsiantar dapat diambil kesimpulan sebagai berikut :

1. Sistem yang dirancang ini adalah Sistem Informasi Front Office untuk reservasi kamar hotel khusus pada bagian resepsionis. Sistem ini dapat memberikan beberapa kelebihan, yaitu efisien dan efektif dalam pengolaan informasi pelanggan, kamar, maupun data transaksi.

2. Dengan adanya Sistem Informasi Front Office untuk reservasi kamar hotel berbasis Vb.Net ini dapat memudahkan pekerjaan para resepsionis dalam menginput pemesanan kamar setiap harinya untuk memaksimalkan kinerja pada bagian resepsi Hotel Fergael dan juga menghemat waktu dalam melakukan pencarian, pencatatan dan pemasukan data pelanggan, kamar, maupun transaksi.

\section{REFERENSI}

[1] V. M. M. Siregar, E. Damanik, M. R. Tampubolon, E. I. Malau, E. P. S. Parapat, and D. S. Hutagalung, "Sistem Informasi Administrasi Pinjaman (Kredit) Pada Credo Union Modifikasi (CUM) Berbasis Web," J. Tekinkom, vol. 3, no. 2, pp. 6269, 2020, doi: 10.37600/tekinkom.v3i2.193.

[2] H. Sugara, E. Sirait, M. A. Hanafiah, and N. F. Siagian, "Sistem Informasi Pembayaran SPP Pada SMK Swasta Teladan Tanah Jawa Menggunakan
Vb.Net," J. Tek. Inf. dan Komput., vol. 3, no. 1, p. 14, 2020, doi: 10.37600/tekinkom.v3i1.125.

[3] S. S. S, A. T. Purba, and V. M. M. Siregar, "Sistem Pendukung Keputusan Kelayakan Pemberian Pinjaman Kredit Menggunakan Metode Topsis Pada Cum Caritas HHKBP Pematangsiantar," J. Tek. Inf. dan Komput., vol. 3, no. 1, p. 1, Sep. 2020, doi: 10.37600/tekinkom.v3i1.117.

[4] A. T. Purba and V. M. M. Siregar, "Sistem Penyeleksi Mahasiswa Baru Berbasis Web Menggunakan Metode Weighted Product," TEKINKOM, vol. 3, no. 1, pp. 1-8, 2020, doi: 10.37600/tekinkom.v3i1.117.

[5] S. P. Tamba, M. D. Batubara, W. Purba, M. Sihombing, V. M. Mulia Siregar, and J. Banjarnahor, "Book data grouping in libraries using the k-means clustering method," J. Phys. Conf. Ser., vol. 1230, no. 1, p. 012074, Jul. 2019, doi: 10.1088/1742-6596/1230/1/012074.

[6] V. M. M. Siregar, H. Sugara, and G. A. Purba, "Aplikasi Pencatatan Laporan Penjualan Kita-Kita.Net Berbasis Web," TEKINKOM, vol. 2, no. 1, pp. 80-86, 2019, doi: 10.37600/tekinkom.v2i1.81.

[7] V. M. M. Siregar, H. Sugara, and I. M. Siregar, "Perancangan Sistem Informasi Pendataan Barang Pada PT. Serdang Hulu," J. Comput. Bisnis, vol. 12, no. 2, pp. 111-117, 2018.

[8] V. M. Siregar and H. Sugara, "Perancangan Dan Implementasi Aplikasi Penggajian Berbasis Dekstop Pada Murni Sadar English Course," J. Tek. Inf. dan Komput., vol. 1, no. 2, pp. 42-48, 2018.

J. Simatupang and S. $\begin{array}{r}\text { Sianturi, } \\ \text { "PISTEM }\end{array}$
INFORMANCANGAN PEMESANAN
TIKET
BUS PADA PO. HANDOYO
BERBASIS ONLINE," J. Intra Tech, vol.
3, no. 2, pp. 11-25, 2019.


[10] Fricles Ariwisanto Sianturi, "Analisa metode teorema bayes dalam mendiagnosa keguguran pada ibu hamil berdasarkan jenis makanan," Tek. Inf. dan Komput., vol. 2, no. 1, pp. 87-92, 2019, [Online]. Available: http://jurnal.murnisadar.ac.id/index.php/ Tekinkom/article/view/78.

[11] A. Ardian, I. Purnama, and V. Sihombing, "Perancangan Aplikasi Pengolah Data Siswa Berbasis Android (Studi Kasus: Mis Nurul Huda Labuhan Batu Selatan)," Pengabdi. Masy. Ika Bina En Pabolo, vol. 1, no. 1, pp. 40-53, 2019.

[12] G. J. Yanris, “Analisis Dan Implementasi Data Mining Dalam Menganalisa Kendala Akademik Yang Sering Dikeluhkan Mahasiswa AMIK Labuhanbatu (Studi Kasus: Amik Labuhanbatu)," Informatika, vol. 4, no. 1, pp. 15-24, 2016.

[13] V. Sihombing, "Aplikasi Simade (Sistem Informasi Manajemen Desa) Dalam Meningkatkan Pelayanan Administrasi di Kepenghuluan Bakti Makmur Kecamatan Bagan Sinembah Kab. Rokan Hilir Riau," SISTEMASI, vol. 7, no. September, pp. 292-297, 2018.

[14] W. Purba, S. Tamba, and J. Saragih, "The effect of mining data k-means clustering toward students profile model drop out potential," J. Phys. Conf. Ser., vol. 1007, no. 1, p. 12049, 2018, [Online]. Available: http://stacks.iop.org/1742$6596 / 1007 / \mathrm{i}=1 / \mathrm{a}=012049$.

[15] V. Sihombing, "Sistem Informasi Penjualan Mobil Suzuki Di Dealer Bagan Batu," SISTEMASI, vol. 7, no. 2, pp. 113119, 2018.

[16] W. Purba, S. Aisyah, and S. P. Tamba, "Perancangan Sistem Pakar Diagnosa Penyakit Mata Katarak Menggunakan Konsep Metode Runut Mundur," JUSIKOM PRIMA (Junal Sist. Inf. Ilmu Komput. Prima), vol. 1, no. 1, 2017.

[17] S. Sirait et al., "Selection of the Best
Administrative Staff Using Elimination Et Choix Traduisant La Realite (ELECTRE) Method," J. Phys. Conf. Ser., vol. 1933, no. 1, p. 012068, Jun. 2021, doi: 10.1088/1742-6596/1933/1/012068.

[18] V. M. M. Siregar, S. Sonang, A. T. Purba, H. Sugara, and N. F. Siagian, "Implementation of TOPSIS Algorithm for Selection of Prominent Student Class," J. Phys. Conf. Ser., vol. 1783, no. 1, p. 012038, Feb. 2021, doi: 10.1088/1742-6596/1783/1/012038.

[19] V. Sihombing et al., "Additive Ratio Assessment (ARAS) Method for Selecting English Course Branch Locations," J. Phys. Conf. Ser., vol. 1933, no. 1, p. 012070, Jun. 2021, doi: 10.1088/1742-6596/1933/1/012070.

[20] V. M. M. Siregar, M. R. Tampubolon, E. P. S. Parapat, E. I. Malau, and D. S. Hutagalung, "Decision support system for selection technique using MOORA method," IOP Conf. Ser. Mater. Sci. Eng., vol. 1088, no. 1, p. 012022, Feb. 2021, doi: 10.1088/1757-899X/1088/1/012022.

[21] V. Sihombing, V. M. M. Siregar, W. S. Tampubolon, M. Jannah, Risdalina, and A. Hakim, "Implementation of simple additive weighting algorithm in decision support system," IOP Conf. Ser. Mater. Sci. Eng., vol. 1088, no. 1, p. 012014, Feb. 2021, doi: 10.1088/1757899X/1088/1/012014.

[22] P. H. Sutanto, N. Lidwan, and W. Ridwan, "Perancangan Reservasi Pariwisata Dan Kamar Hotel Berbasis Web Jisamar," JISAMAR ( J. Inf. Syst. , Appl. , Manag. , Account. Researh), vol. 4, no. 4, pp. 3948, 2020, [Online]. Available: http://journal.stmikjayakarta.ac.id/index. php/jisamar/article/view/274/199.

[23] A. Prabowo et al., "Sistem Informasi Reservasi Kamar Hotel Pada Hotel Posters MICE," J. Mhs. Bina Insa., vol. 1, no. 2, pp. 147-160, 2017. 